\title{
Stopped-flow study of the enhanced chemiluminescence for the oxidation of luminol with hydrogen peroxide catalyzed by microperoxidase 8
}

\author{
Hui-Chun Yeh, Wann-Yin Lin* \\ Department of Chemistry, National Taiwan University, Taipei 106, Taiwan, ROC
}

Received 18 June 2002; received in revised form 9 December 2002; accepted 16 December 2002

\begin{abstract}
The presence of carbonate or Tris causes a dramatic enhancement in the cheminluminescence (CL) for the oxidation of luminol with hydrogen peroxide catalyzed by microperoxidase 8 (MP8). A nearly constant enhancement in CL was observed over a wide range of $\mathrm{H}_{2} \mathrm{O}_{2}$ and luminol concentrations. The enhancement in $\mathrm{CL}$ is strongly pH-dependent, varying from 1.3 to 22.2 for carbonate and 1.6 to 10.2 for Tris. The $\mathrm{CL}$ enhancement is much more prominent at $\mathrm{pH} 9-$ 10 than at high $\mathrm{pH}(>10.5)$ because of the extremely weak CL emission at $\mathrm{pH}$ below 10 when no enhancer is present. The CL enhancement is attributed to an accelerated CL cycle and the existence of alternative routes for luminol CL, possibly involving the carbonate, or Tris radicals. The dramatic enhancement in CL of the MP8-luminol- $\mathrm{H}_{2} \mathrm{O}_{2}$ system by the readily available reagents, sodium carbonate or Tris, will have general applications for sensitive CL assays. As an example, the presence of antioxidant results in a diminished and delayed CL emission, allowing the determination of its concentration at sub-micromolar level.
\end{abstract}

(C) 2003 Elsevier Science B.V. All rights reserved.

Keywords: Stopped-flow; Chemiluminescence; MP8; Luminol; $\mathrm{Na}_{2} \mathrm{CO}_{3}$; Tris

\section{Introduction}

Cheminluminescence (CL) results from light being emitted in an exothermic chemical reaction. CL finds many applications in the determination of a variety of compounds [1,2]. Any one of the reaction components, including CL substrate, oxidant, catalyst, cofactor, sensitizer, enhancer,

\footnotetext{
* Corresponding author. Fax: +886-2-2363-6359.

E-mail address: wylin@ccms.ntu.edu.tw (W.-Y. Lin).
}

and inhibitor can be made rate limiting and hence be determined. CL emission from the oxidation of luminol is one of the best-known systems. The oxidation is usually conducted in a basic solution in the presence of an oxidant and a catalyst. A number of oxidants (e.g. hydrogen peroxide [3], hypochlorite [4], iodine [5], chlorine dioxide [6], persulfate [7], or dissolved oxygen [8]) and catalysts (e.g. peroxidases such as horseradish peroxidase (HRP) [9], lactoperoxidase [9], myleoperoxidase [10] and metal ions such as $\mathrm{Co}(\mathrm{II}), \mathrm{Fe}(\mathrm{II}), \mathrm{Cu}(\mathrm{II})$ [1]) have been reported. 
Among them, HRP-luminol- $\mathrm{H}_{2} \mathrm{O}_{2}$ is most popular and has been employed in many CL assays [1]. Moreover, a variety of enhancers (e.g. phenolic derivatives [11], chemical indicators [12], surfactant [13]) have been developed to further increase its CL intensity. However, HRP and other peroxidases are usually employed in somewhat mild conditions, owing to the necessity of maintaining the integrity of the protein structure. An attractive catalyst with peroxidase activity is microperoxidase (MP). MP contains a covalently linked oligopeptide (e.g. with eight amino acids for Fe(III)-MP8 or simply MP8) and does not require to maintain a native peptide structure to function properly. MP-catalyzed oxidation of luminol by hydrogen peroxide has been employed to determine a variety of substances, including peroxides [1], antioxidants [14], catecholamines [15]. The enhancers normally used in the $\mathrm{HRP}-\mathrm{H}_{2} \mathrm{O}_{2}$-luminol system have no enhancing effect on the CL emission involving MP.

In this paper, we found that the presence of carbonate or Tris dramatically enhances the CL emission of the MP8- $\mathrm{H}_{2} \mathrm{O}_{2}$-luminol system over a wide $\mathrm{pH}$ range. We have investigated the effect of $\mathrm{pH}$, the concentrations of hydrogen peroxide and luminol on the peak CL intensity for the MP8$\mathrm{H}_{2} \mathrm{O}_{2}$-luminol system in the presence or absence of enhancer. The mechanism of $\mathrm{CL}$ enhancement in terms of the acceleration of the CL cycle has been discussed. The feasibility of applying this enhanced CL system to the determination of antioxidants has also been demonstrated.

\section{Experimental}

\subsection{Materials}

Ascorbic acid, cytochrome $c$, luminol (5-amino2,3-dihydrophthalazine-1,4-dione), pepsin, sodium hydrogen phosphate, sodium phosphate, tris[hydroxymethyl] aminomethane (Tris), trypsin and uric acid were purchased from Sigma (USA). Sodium carbonate was obtained from Acros organics company (Belgium). All reagents were of the highest grade of purity. Water was obtained from a Milli-Q purification system (Japan Milli- pore, Tokyo). The stock solution of hydrogen peroxide (Fluka, Germany) was prepared by volumetric dilution of $30 \%(\mathrm{w} / \mathrm{w}) \mathrm{H}_{2} \mathrm{O}_{2}$. The concentration of $\mathrm{H}_{2} \mathrm{O}_{2}$ was determined daily by measuring the UV absorbance at $240 \mathrm{~nm}$ using $\varepsilon_{240}=39.4 \mathrm{M}^{-1} \mathrm{~cm}^{-1}[16]$. The stock solutions of luminol, sodium carbonate and Tris were prepared by dissolving a precisely weighed solid in $5 \mathrm{mM}$ phosphate buffer. MP8 was prepared from the proteolytic digestion of cytochrome $c$ with pepsin and trypsin according to the procedure in the literature [17]. The concentration of MP8 was determined from the absorbance at $397 \mathrm{~nm}$ using $\varepsilon_{397}=1.57 \times 10^{5} \mathrm{M}^{-1} \mathrm{~cm}^{-1}$ at pH 7.0 [18].

\subsection{Stopped-flow CL and kinetic measurements}

All the CL and kinetic measurements were performed on a Hitech SF-61 stopped-flow spectrofluorimeter (Hitech Scientific, UK) as described previously [19]. The CL experiments were performed in the fluorescence mode with the light source being switched off. The MP8 solution was stored in one syringe and the luminol- $\mathrm{H}_{2} \mathrm{O}_{2}$ mixture in the other. The time course of $\mathrm{CL}$ emission was recorded immediately after mixing the solutions in the two syringes. In the $\mathrm{pH}$ dependence experiments, both solutions in the two syringes were adjusted to the desired $\mathrm{pH}$ using saturated $\mathrm{NaOH}$ and $12 \mathrm{M} \mathrm{HCl}$ with a $\mathrm{pH}$ meter (Model 6071, Jenco Electronics Ltd). For measuring the rates of formation of the intermediate, the changes in absorbance at $415 \mathrm{~nm}$ were monitored continuously after mixing MP8 and $\mathrm{H}_{2} \mathrm{O}_{2}$ in two separate syringes. The stopped-flow experiments were operated in the absorption mode and the PMT voltage was set at $200 \mathrm{~V}$. For measuring the rate of the reaction of intermediate with luminol, MP8 and $\mathrm{H}_{2} \mathrm{O}_{2}$ were premixed in one syringe, while luminol was stored in the other. After an appropriate delay time $(5-10 \mathrm{~s})$ to accumulate a maximum amount of intermediate, the two solutions were mixed and the change in absorbance at $415 \mathrm{~nm}$ was recorded continuously. The built-in software of the stopped-flow instrument allows one- or two-exponential fitting of the traces. All the stopped-flow experiments were carried at $25^{\circ} \mathrm{C}$. 


\subsection{Continuous flow apparatus and procedure}

A schematic diagram of the set-up for the determination of the CL emission spectrum was shown in Fig. 1. The flow solution in R1 contains $5 \mu \mathrm{M}$ MP8, while R2 contains $100 \mu \mathrm{M}$ luminol and $5 \mu \mathrm{M} \mathrm{H}_{2} \mathrm{O}_{2}$. Both solutions contain $0.5 \mathrm{M} \mathrm{Na}_{2} \mathrm{CO}_{3}$ in $5 \mathrm{mM}$ phosphate buffer at $\mathrm{pH} 10.0$. The solutions were pumped by a peristaltic pump (Gilson minipuls) through a PEEK Tee $(0.566 \mu$, model P.727, Upchurch Scientific, USA) at a rate of $1.1 \mathrm{ml} \mathrm{min}-1$. The PEEK tubing (0.0625 in. OD, 0.02 in. ID, Upchurch Scientific) was used to connect the reagent streams to the Tee and from Tee to flow cell $(10 \mathrm{~cm})$. The $\mathrm{CL}$ emission spectrum was recorded with a fluorescence spectrophotometer (F-2000, Hitachi, Japan) via a LC Micro Flow Cell Unit (18 $\mu 1$, model 650-0151, Hitachi, Japan), which permits a high-sensitivity, low-scattering beam level measurement and can be used in a high-speed liquid chromatography.

\section{Results and discussion}

\subsection{Effect of sodium carbonate and Tris concentrations on chemiluminescence}

Stopped-flow method is a powerful technique to detect the short-lived CL, which ensures rapid and reproducible mixing of reagents and allows full intensity versus time profiles to be obtained. Fig. 2 shows the stopped-flow CL intensity versus time profiles for the reactions of $2.4 \mu \mathrm{M}$ MP8, $2.4 \mu \mathrm{M}$ $\mathrm{H}_{2} \mathrm{O}_{2}$ and $50 \mu \mathrm{M}$ luminol in $5 \mathrm{mM}$ phosphate buffer $(\mathrm{pH} 10.0)$ at various concentrations of

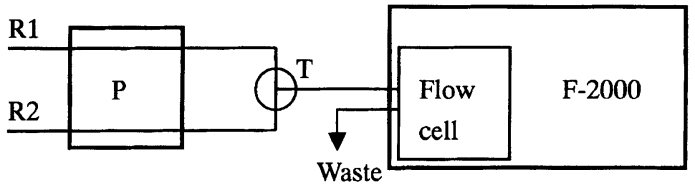

Fig. 1. Schematic diagram of the continuous flow manifold for the detection of the $\mathrm{CL}$ emission spectrum. R1, solution containing $5 \mu \mathrm{M}$ MP8 in $0.5 \mathrm{M} \mathrm{Na}_{2} \mathrm{CO}_{3}$ at $\mathrm{pH} 10.0$; R2, solution containing $100 \mu \mathrm{M}$ luminol; $5 \mu \mathrm{M} \mathrm{H}_{2} \mathrm{O}_{2}$ in $0.5 \mathrm{M}$ $\mathrm{Na}_{2} \mathrm{CO}_{3}$ at $\mathrm{pH}$ 10.0; $\mathrm{P}$, peristaltic pump; T, mixing Tee; F-2000, fluorimeter.
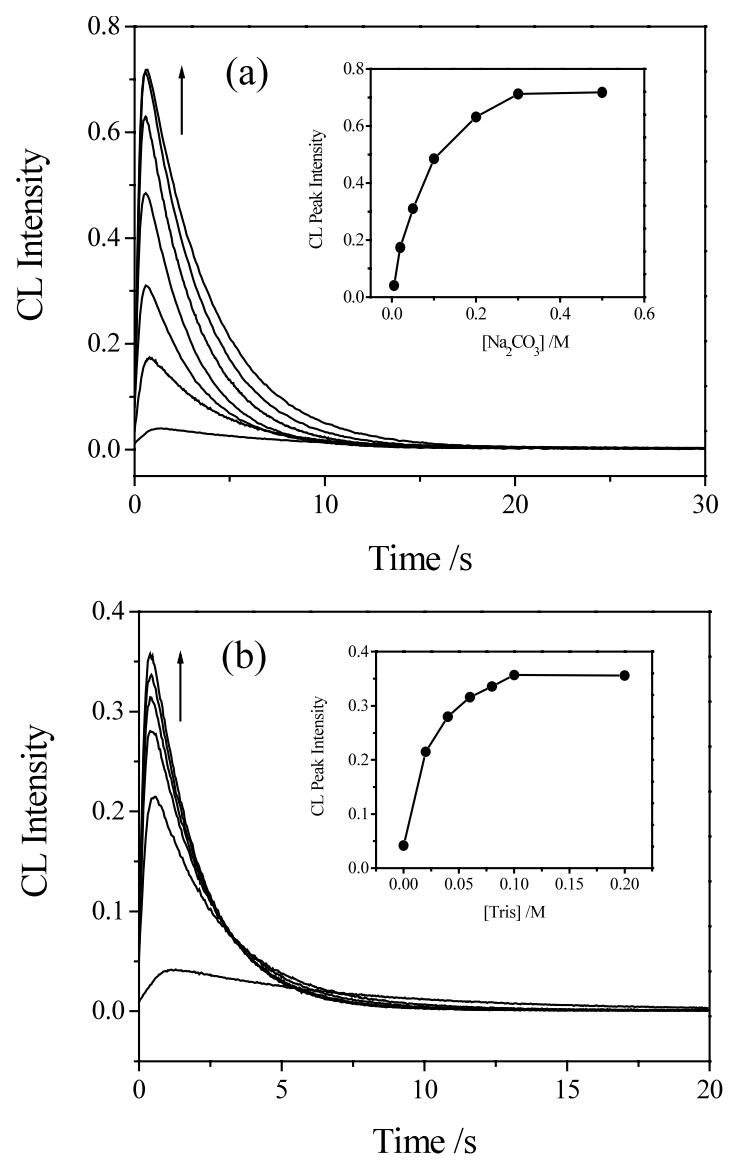

Fig. 2. Effects of the concentrations of (a) $\mathrm{Na}_{2} \mathrm{CO}_{3}$ and (b) Tris on the stopped-flow CL intensity vs. time profiles and the peak $\mathrm{CL}$ intensities (inset) for the reactions of $2.4 \mu \mathrm{M} \mathrm{MP8,} 2.4 \mu \mathrm{M}$ $\mathrm{H}_{2} \mathrm{O}_{2}$, and $50 \mu \mathrm{M}$ luminol in $5 \mathrm{mM}$ phosphate buffer at $\mathrm{pH}$ 10.0. Reagent concentrations (from bottom to top): $\left[\mathrm{Na}_{2} \mathrm{CO}_{3}\right]=0,0.02,0.05,0.1,0.2,0.3$, and $0.5 \mathrm{M}$. [Tris] $=0$, $0.02,0.04,0.06,0.08$, and $0.1 \mathrm{M}$.

$\mathrm{Na}_{2} \mathrm{CO}_{3}$ or Tris. The presence of an increasing concentration of $\mathrm{Na}_{2} \mathrm{CO}_{3}$ causes a dramatic enhancement of its $\mathrm{CL}$ intensity with no significant change in the CL duration as illustrated in Fig. 2a. A maximum enhancement in peak CL intensity (denoted as $\mathrm{CL}_{\mathrm{r}}$, which is the relative peak $\mathrm{CL}$ intensities obtained in the presence and in the absence of an enhancer) of $19.0 \pm 0.4(n=10)$ was achieved when the concentration of $\mathrm{Na}_{2} \mathrm{CO}_{3}$ is above $0.3 \mathrm{M}$ (Fig. 2a, inset). Significant enhancement in CL intensity accompanied by a concomitant reduction in CL duration was observed as the 
concentration of Tris was increased (Fig. 2b). A maximum value of $\mathrm{CL}_{\mathrm{r}}$ of $9.2 \pm 0.2(n=10)$ was obtained when the concentration of Tris is above $0.1 \mathrm{M}$ (Fig. 2b, inset).

\subsection{Effects of luminol and hydrogen peroxide concentrations}

Having found the drastic enhancement in CL intensity caused by $\mathrm{Na}_{2} \mathrm{CO}_{3}$ and Tris, it is also important to investigate how the changes in concentrations of luminol and $\mathrm{H}_{2} \mathrm{O}_{2}$ affect the $\mathrm{CL}$ emission when the enhancer is present. Fig. 3 shows the double-log plots for the peak CL intensity versus the concentration of luminol for the reactions of $2.4 \mu \mathrm{M}$ MP8, $2.4 \mu \mathrm{M} \mathrm{H}_{2} \mathrm{O}_{2}$ in 5 $\mathrm{mM}$ phosphate buffer at $\mathrm{pH} 10.0$ with or without the presence of an enhancer. All the three plots are linear and nearly parallel in the range of $2-20 \mu \mathrm{M}$ of luminol, indicating that the CL enhancement $\left(\mathrm{CL}_{\mathrm{r}}=\sim 10\right.$-fold for Tris, $\sim 20$-fold for $\left.\mathrm{Na}_{2} \mathrm{CO}_{3}\right)$ does not change appreciably in this concentration range. The maximum peak CL intensity occurs at $\sim 50 \mu \mathrm{M}$ of luminol. The stopped-flow $\mathrm{CL}$ intensity versus time profiles (data not shown) have revealed that both the peak intensity and the total emission (i.e. the area under the CL profile) increase rapidly as the concentration of luminol

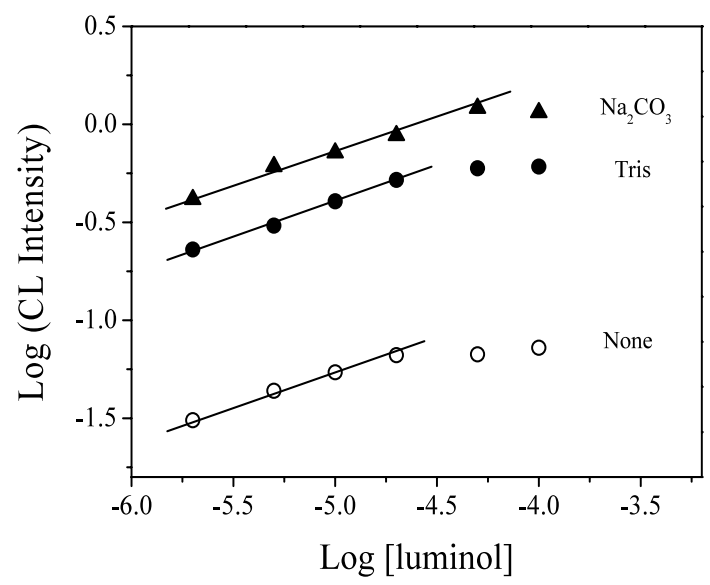

Fig. 3. The double-log plots of the peak CL intensity vs. the concentration of luminol for the reactions of $2.4 \mu \mathrm{M}$ MP8 and $2.4 \mu \mathrm{M} \mathrm{H}_{2} \mathrm{O}_{2}$ in $5 \mathrm{mM}$ phosphate buffer $(\mathrm{pH} \mathrm{10)}$ and in the presence of $(\bigcirc)$ none, ( $\mathbf{\Delta}) 0.5 \mathrm{M} \mathrm{Na}_{2} \mathrm{CO}_{3}$, and (O) $0.1 \mathrm{M}$ Tris. increases until a maximum value is achieved at a saturation level of luminol.

Fig. 4 shows the double-log plot for the peak CL intensity versus the concentration of $\mathrm{H}_{2} \mathrm{O}_{2}$ for the reactions of $2.4 \mu \mathrm{M} \mathrm{MP} 8,50 \mu \mathrm{M}$ luminol $(\mathrm{pH}$ 10.0 ) in the presence of $0.5 \mathrm{M} \mathrm{Na}_{2} \mathrm{CO}_{3}$. The plot is linear with a slope of 1.018 and spans four orders of magnitude over the concentration of $\mathrm{H}_{2} \mathrm{O}_{2}$. Similar linear plot (at $\sim 0.3 \log$-unit below the straight line in Fig. 4) was also observed for the CL experiment obtained in the presence of $0.1 \mathrm{M}$ Tris (data not shown). The stopped-flow CL intensity versus time profiles (data not shown) indicate that the $\mathrm{CL}$ duration remains nearly constant when the concentration of $\mathrm{H}_{2} \mathrm{O}_{2}$ is below $0.2 \mathrm{mM}$, whereas it decreases significantly if the concentration of $\mathrm{H}_{2} \mathrm{O}_{2}$ is above $0.2 \mathrm{mM}$. The reduction in CL duration at high concentration of $\mathrm{H}_{2} \mathrm{O}_{2}$ is probably due to the partial degradation of the intermediate of MP8 [20] and an insufficient supply of luminol to sustain a fast CL cycle.

\section{3. $p H$ dependence of the chemiluminescence}

Since the activity of MP8 and the efficiency of luminol-CL are all strongly $\mathrm{pH}$-dependent, it is interesting to examine how the $\mathrm{pH}$ affects the $\mathrm{CL}$ emission of the MP8-luminol- $\mathrm{H}_{2} \mathrm{O}_{2}$ system. Fig. 5a shows the $\mathrm{pH}$ dependence of the peak CL intensity in the absence or presence of $0.5 \mathrm{M} \mathrm{Na}_{2} \mathrm{CO}_{3}$ (or $0.1 \mathrm{M}$ Tris). The maximum CL emission occurs at pH 11.0 for $0.1 \mathrm{M}$ Tris, $\mathrm{pH} 10-12$ for $\mathrm{Na}_{2} \mathrm{CO}_{3}$ and $\mathrm{pH} 12.5$ in the absence of an enhancer. The peak

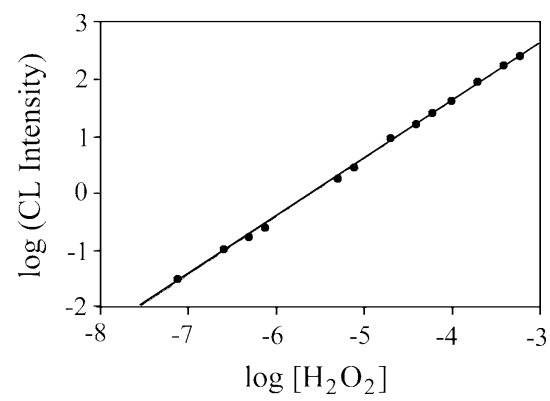

Fig. 4. The double-log plot of the peak CL intensity vs. the concentration of $\mathrm{H}_{2} \mathrm{O}_{2}$ for the reactions of $2.4 \mu \mathrm{M}$ MP8, $50 \mu \mathrm{M}$ luminol and $0.5 \mathrm{M} \mathrm{Na}_{2} \mathrm{CO}_{3}$ in $5 \mathrm{mM}$ phosphate buffer at $\mathrm{pH}$ 10.0 . 

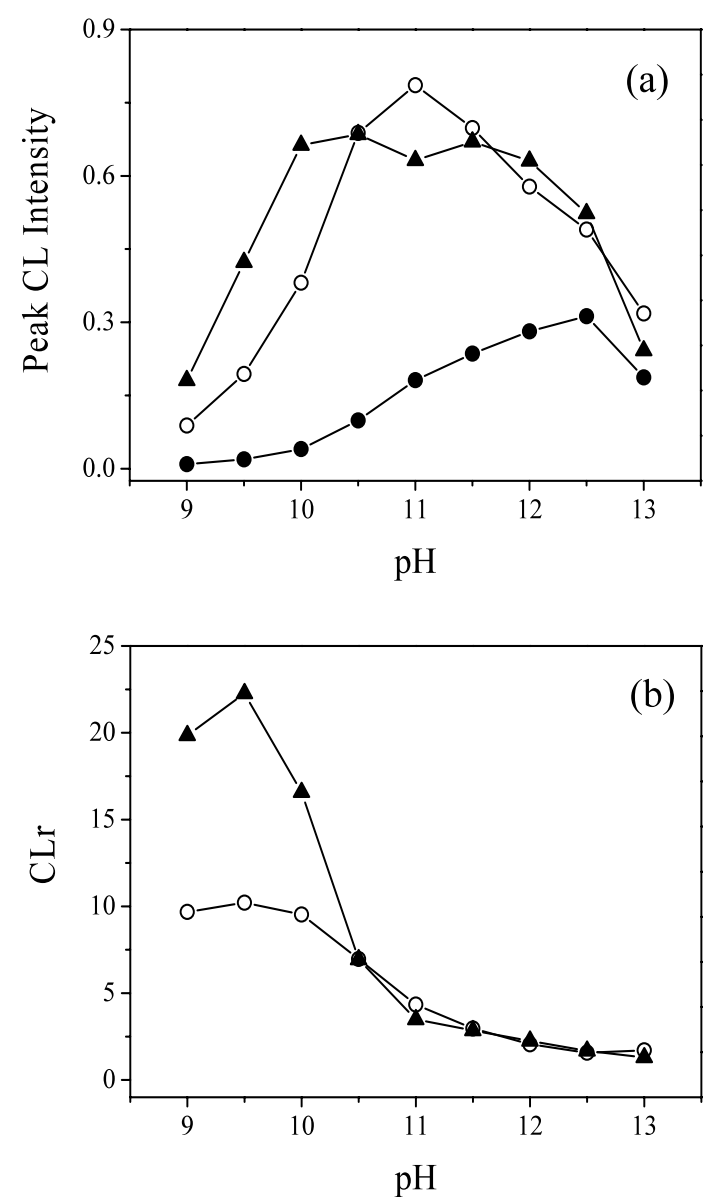

Fig. 5. (a) $\mathrm{pH}$ dependence of the peak $\mathrm{CL}$ intensities for the reactions of $2.4 \mu \mathrm{M} \mathrm{MP} 8,2.4 \mu \mathrm{M} \mathrm{H}_{2} \mathrm{O}_{2}$, and $50 \mu \mathrm{M}$ luminol in $5 \mathrm{mM}$ phosphate buffer at various $\mathrm{pH}$ in the presence of $(\mathbf{O})$ none, (ム) $0.5 \mathrm{M} \mathrm{Na} \mathrm{CO}_{3}$, and (O) $0.1 \mathrm{M}$ Tris; (b) $\mathrm{pH}$ dependence of the $\mathrm{CL}$ enhancement $\left(\mathrm{CL}_{\mathrm{r}}\right)$.

CL intensity is nearly an order of magnitude smaller at $\mathrm{pH} 10.0$ than at 12.5 when the enhancer is absent. However, the peak $\mathrm{CL}$ intensity in the presence of $0.5 \mathrm{M} \mathrm{Na}_{2} \mathrm{CO}_{3}$ or 0.1 Tris in the $\mathrm{pH}$ range of 10-12.5 is larger than the maximum peak $\mathrm{CL}$ intensity (at $\mathrm{pH} 12.5$ ) without the enhancer by $20-150 \%$, allowing the employment of the enhanced $\mathrm{CL}$ for sensitive assays over a wide $\mathrm{pH}$ range. The $\mathrm{CL}$ emission from the oxidation of luminol with $\mathrm{H}_{2} \mathrm{O}_{2}$ catalyzed by peroxidases was usually carried out under slightly alkaline $\mathrm{pH}$. For example, pH 8.5 was employed for HRP [9] and pH 7.5 for myleoperoxidase [10]. However, only extremely weak CL emission was observed for these enzyme-catalyzed CL systems in the range of pH 10-12 (i.e. optimal for the MP8-catalyzed CL emission in the presence of the enhancer) due to the low activity of these enzymes in this $\mathrm{pH}$ range. Moreover, addition of $\mathrm{Na}_{2} \mathrm{CO}_{3}$ or Tris shows no enhancement in $\mathrm{CL}$ emission for the peroxidasecatalyzed CL systems (data not shown).

Enhancement of the CL emission caused by $\mathrm{Na}_{2} \mathrm{CO}_{3}$ or Tris was observed in the entire $\mathrm{pH}$ range but to a different extent. The $\mathrm{pH}$ dependence of $\mathrm{CL}_{\mathrm{r}}$ is shown in Fig. 5b. The values of $\mathrm{CL}_{\mathrm{r}}$ vary from 1.3 to 22.2 for $\mathrm{Na}_{2} \mathrm{CO}_{3}$ and 1.6 to 10.2 for Tris. The enhancement is much more prominent at $\mathrm{pH} 9-10$ than at high $\mathrm{pH}(>10.5)$ because of the extremely weak CL emission at $\mathrm{pH}$ below 10 in the absence of the enhancer. The stopped-flow CL intensity versus time profiles in the absence of an enhancer (data not shown) have demonstrated that the CL intensity, CL duration and total CL emission all increase rapidly as the $\mathrm{pH}$ rises from 9.0 to 12.5 . These results are consistent with a much better CL-efficiency at higher $\mathrm{pH}$ than at lower $\mathrm{pH}$, normally observed for the luminol system.

\subsection{Effects of $\mathrm{Na}_{2} \mathrm{CO}_{3}$ and Tris on the rate of the CL cycle}

To examine why $\mathrm{Na}_{2} \mathrm{CO}_{3}$ and Tris cause the $\mathrm{CL}$ enhancement, it is necessary to understand the mechanism of the CL emission. Luminol is a diprotic acid (denoted as $\mathrm{LH}_{2}$ ) with two $\mathrm{p} K_{\mathrm{a}}$ values of 6 and $\sim 13$ [21]. In the $\mathrm{pH}$ range of $9-$ 13 employed in this study, luminol exists mostly as $\mathrm{LH}^{-}$. The mechanism of the CL emission, adapted from that of the peroxidase-luminol$\mathrm{H}_{2} \mathrm{O}_{2}$ system [22], generally involves the following steps:

$$
\begin{aligned}
& \mathrm{MP} 8+\mathrm{HO}_{2}^{-} \rightarrow \mathrm{X}+\mathrm{OH}^{\cdot} \\
& \mathrm{X}+\mathrm{LH}^{-}+\mathrm{OH}^{-} \rightarrow \mathrm{MP} 8+\mathrm{L}^{-}+\mathrm{H}_{2} \mathrm{O} \\
& 2 \mathrm{~L}^{\cdot}+\mathrm{H}_{2} \mathrm{O} \rightarrow \mathrm{L}+\mathrm{LH}^{-}+\mathrm{OH}^{-} \\
& \mathrm{L}+\mathrm{H}_{2} \mathrm{O}_{2} \rightarrow 3 \mathrm{AP}+\mathrm{N}_{2}+\text { light }
\end{aligned}
$$

The first step is the transfer of an oxygen atom from the oxidant to the peroxidase to form a reactive intermediate $(\mathrm{X})$. The second step is the 
abstraction of a hydrogen atom from luminol $\left(\mathrm{LH}^{-}\right)$by the intermediate to produce a luminol radical $\left(\mathrm{L}^{\cdot-}\right)$. Step 3 is the disproportionation of two luminol radicals to yield diazaquinone (L) and luminol $\left(\mathrm{LH}^{-}\right)$. Step 4 is the reaction of diazaquinone with $\mathrm{H}_{2} \mathrm{O}_{2}$ to give the final product 3aminophthalate (3-AP), accompanied by an emission of light. According to the mechanism, any factor that facilitates the formation of the intermediates and/or the luminol radical will tend to enhance the CL intensity.

The formation of the intermediates can be monitored by the stopped-flow technique using the photodiode array detection. Fig. 6 shows the time-resolved difference spectra for the reaction of $2.4 \mu \mathrm{M}$ MP8 and $2.4 \mu \mathrm{M} \mathrm{H}_{2} \mathrm{O}_{2}$ in $5 \mathrm{mM}$ phosphate buffer at $\mathrm{pH}$ 10.0. Upon addition of $\mathrm{H}_{2} \mathrm{O}_{2}$ to Fe(III)-MP8, new difference bands appear at 415, 522, and $549 \mathrm{~nm}$. These spectral features are characteristics of the intermediate $\mathrm{O}=\mathrm{Fe}(\mathrm{IV}) \mathrm{MP} 8$, analogous to compound II of HRP or catalase [23]. The rate of the formation of the intermediate can be determined by following the change in absorbance at $415 \mathrm{~nm}\left(A_{415}\right)$. Fig. 7a shows the time courses for the changes in $A_{415}$ for the oxidation of $2.4 \mu \mathrm{M}$ MP8 by $2.4 \mu \mathrm{M} \mathrm{H}_{2} \mathrm{O}_{2}$ in 5 $\mathrm{mM}$ phosphate buffer at $\mathrm{pH} 10.0$ in the presence or absence of $0.5 \mathrm{M} \mathrm{Na}_{2} \mathrm{CO}_{3}$, or $0.1 \mathrm{M}$ Tris. The presence of $\mathrm{Na}_{2} \mathrm{CO}_{3}$ or Tris significantly accelerates the rate of the formation of the intermediate. The stopped-flow trace in buffer can be fit nicely with a single exponential function, which yields an apparent rate constant $\left(k_{1}\right)$ of $0.31 \pm 0.01 \mathrm{~s}^{-1}$ for the formation of $\mathrm{X}$. The stopped-flow traces obtained in the presence of $\mathrm{Na}_{2} \mathrm{CO}_{3}$ or Tris can be fit with a double exponential function. The fast step corresponds to the formation of $\mathrm{X}$. The apparent rate constants relative to that obtained in the buffer $\left(k_{1 \mathrm{r}}\right)$ are given in Table 1 . The values $k_{1 \mathrm{r}}$ are $4.39 \pm 0.08$ and $3.65 \pm 0.05$ for $\mathrm{Na}_{2} \mathrm{CO}_{3}$ and Tris, respectively.

The reaction of the intermediate $\mathrm{X}$ with luminol can be followed by the disappearance of $A_{415}$ as illustrated in Fig. 7b. A single exponential fitting of the stopped-flow trace yields a rate constant $\left(k_{2}\right)$ of $4.82 \pm 0.29 \mathrm{~s}^{-1}$ for step 2. Similar experiments were also carried out for this process in the presence of $0.5 \mathrm{M} \mathrm{Na}_{2} \mathrm{CO}_{3}$ or $0.1 \mathrm{M}$ Tris. The rate constants relative to that obtained in the buffer $\left(k_{2 \mathrm{r}}\right)$ are also given in Table 1 . The values of $k_{2 \mathrm{r}}$ are $0.71 \pm 0.07$ and $0.95 \pm 0.08$ for $\mathrm{Na}_{2} \mathrm{CO}_{3}$ and Tris, respectively. The presence of $\mathrm{Na}_{2} \mathrm{CO}_{3}$ or Tris actually decelerates the rate for the reaction of $\mathrm{X}$ and luminol by 5 and $30 \%$, respectively. The

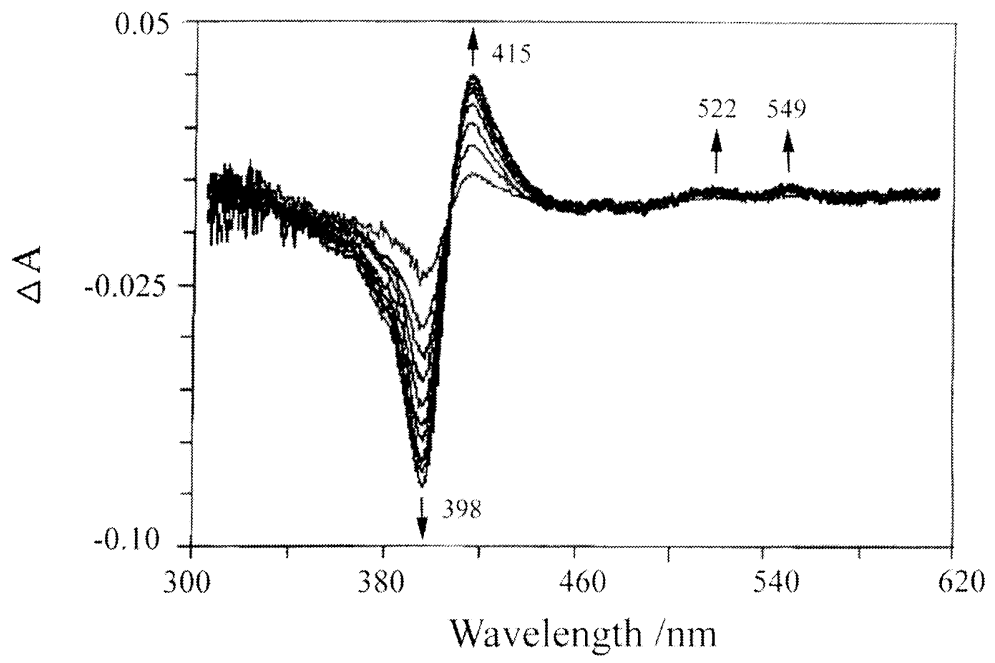

Fig. 6. Stopped-flow time-resolved difference absorption spectra for the oxidation of the $2.4 \mu \mathrm{M}$ MP8 and $2.4 \mu \mathrm{M} \mathrm{H} \mathrm{H}_{2}$ in $5 \mathrm{mM}$ phosphate buffer at $\mathrm{pH} 10.0$. 

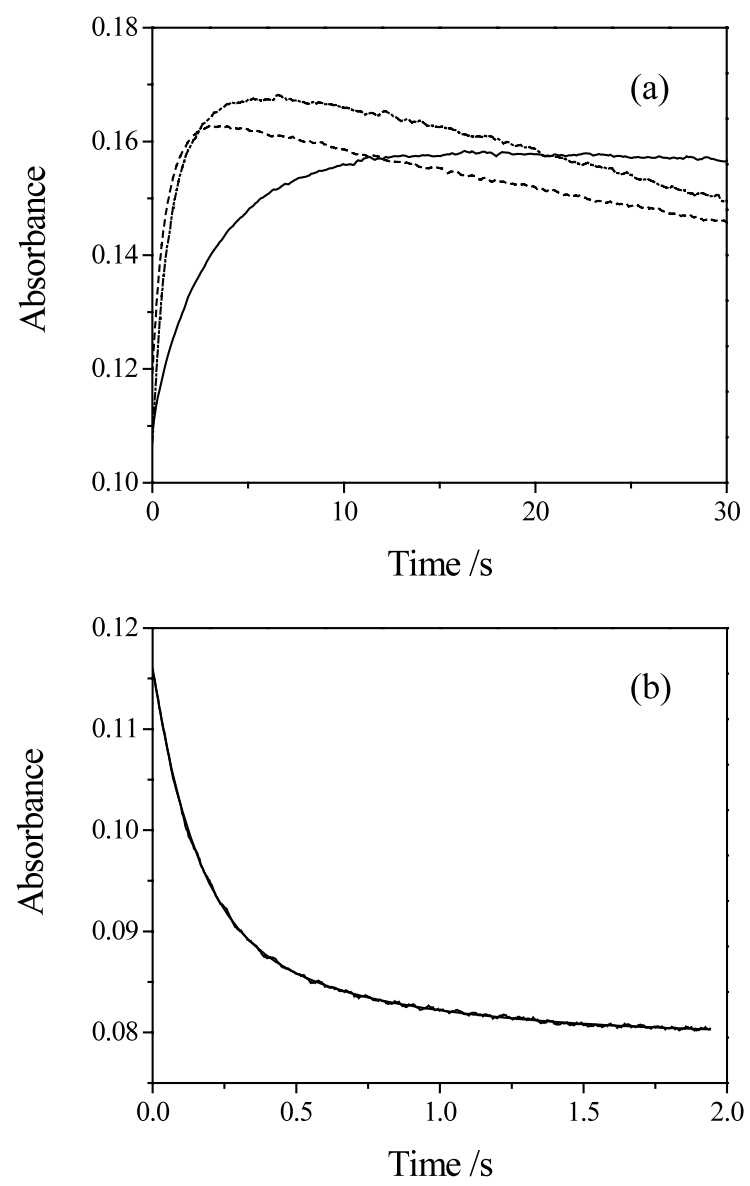

Fig. 7. (a) Time courses for the changes in absorbance at 415 $\mathrm{nm}\left(A_{415}\right)$ for the oxidation of $2.4 \mu \mathrm{M} \mathrm{MP} 8$ by $2.4 \mu \mathrm{M} \mathrm{H}_{2} \mathrm{O}_{2}$ in $5 \mathrm{mM}$ phosphate buffer at $\mathrm{pH} 10.0$ in the presence of none $(-)$, $0.5 \mathrm{M} \mathrm{Na}_{2} \mathrm{CO}_{3}(--)$, and $0.1 \mathrm{M}$ Tris (- - - ) . (b) Time course for the change in $A_{415}$ for the reaction of the intermediate with $20 \mu \mathrm{M}$ luminol.

combined effect of $k_{1 \mathrm{r}}$ and $k_{2 \mathrm{r}}$ has revealed that the presence of $0.5 \mathrm{M} \mathrm{Na}_{2} \mathrm{CO}_{3}$ or $0.1 \mathrm{M}$ Tris accelerates the CL cycle by $3.12 \pm 0.06$ and $3.47 \pm 0.07$, respectively.
The net acceleration of steps 1 and 2 accounts for only $16 \%(3.12 / 19.0)$ and $38 \%(3.47 / 9.2)$ of the observed $\mathrm{CL}$ enhancement for $\mathrm{Na}_{2} \mathrm{CO}_{3}$ and Tris, respectively. The results suggest that there must exist some alternative routes of CL emission when $\mathrm{Na}_{2} \mathrm{CO}_{3}$ or Tris is present. The intermediate $\mathrm{X}$ does not seem to react appreciably with carbonate or Tris since the presence of the enhancers decrease the rate of disappearance of $\mathrm{X}\left(k_{2 \mathrm{r}}<1\right)$. Although the slow step in Fig. 7a may correspond to the reaction of $\mathrm{X}$ with carbonate or Tris. However, the reaction is so slow (its rate is two orders of magnitude smaller than that of the reaction of $\mathrm{X}$ and luminol) that it will not contribute significantly to the enhancement of CL. We have also done some control experiments. No CL emission was observed under the same experimental conditions for $\mathrm{H}_{2} \mathrm{O}_{2}-\mathrm{Na}_{2} \mathrm{CO}_{3}$-luminol, MP8- $\mathrm{Na}_{2} \mathrm{CO}_{3}$-luminol, MP8- $\mathrm{H}_{2} \mathrm{O}_{2}-\mathrm{Na}_{2} \mathrm{CO}_{3}$, and all possible combinations of any two reagents among MP8, $\mathrm{Na}_{2} \mathrm{CO}_{3}$, luminol, and $\mathrm{H}_{2} \mathrm{O}_{2}$.

\subsection{Measurement of the CL emission spectrum}

Measurement of the spectrum of the CL emission is helpful to identify the chemiluminescent species, which is important in understanding the $\mathrm{CL}$ enhancement. The CL reactions last only a few seconds, making the direct measurement of the spectrum of the CL emission using an ordinary fluorimeter very difficult. We have designed a continuous flow manifold in conjunction with a fluorescence spectrometer (Fig. 1) to measure the emission spectrum of the CL system. By adjusting the flow rate, a steady-state CL signal was achieved for the CL reaction of $2.5 \mu \mathrm{M}$ MP8, 2.5 $\mu \mathrm{M} \mathrm{H} \mathrm{H}_{2} \mathrm{O}_{2}, 50 \mu \mathrm{M}$ luminol, $0.5 \mathrm{M} \mathrm{Na}_{2} \mathrm{CO}_{3}$ at $\mathrm{pH}$ 10.0 as demonstrated in Fig. 8a. With the estab-

Table 1

Effects of $\mathrm{Na}_{2} \mathrm{CO}_{3}$ and Tris on the values of $k_{1 \mathrm{r}}, k_{2 \mathrm{r}}, k_{1 \mathrm{r}} \times k_{2 \mathrm{r}}$, and $\mathrm{CL}_{\mathrm{r}}$

\begin{tabular}{llllr}
\hline Enhancer & $k_{1 \mathrm{r}}{ }^{\mathrm{a}}$ & $k_{2 \mathrm{r}}{ }^{\mathrm{b}}$ & $k_{1 \mathrm{r}} \times k_{2 \mathrm{r}}$ & $\mathrm{CL}_{\mathrm{r}}{ }^{\mathrm{c}}$ \\
\hline $0.5 \mathrm{M} \mathrm{Na}_{2} \mathrm{CO}_{3}$ & $4.39 \pm 0.08$ & $0.71 \pm 0.07$ & $3.12 \pm 0.06$ & $19.0 \pm 0.4$ \\
$0.1 \mathrm{M} \mathrm{Tris}$ & $3.65 \pm 0.05$ & $0.95 \pm 0.08$ & $3.47 \pm 0.07$ & $9.2 \pm 0.2$ \\
\hline
\end{tabular}

${ }^{\text {a }} k_{1 \mathrm{r}}$ : relative rate constant (with enhancer/without) of intermediate formation for the reaction of MP8 and $\mathrm{H}_{2} \mathrm{O}_{2}$.

${ }^{\mathrm{b}} k_{2 \mathrm{r}}$ : relative rate constant (with enhancer/without) for the reaction of intermediate and luminol.

${ }^{c} \mathrm{CL}_{\mathrm{r}}$ : relative peak CL intensity (with enhancer/without) for the $\mathrm{MP} 8-\mathrm{H}_{2} \mathrm{O}_{2}$-luminol system. 

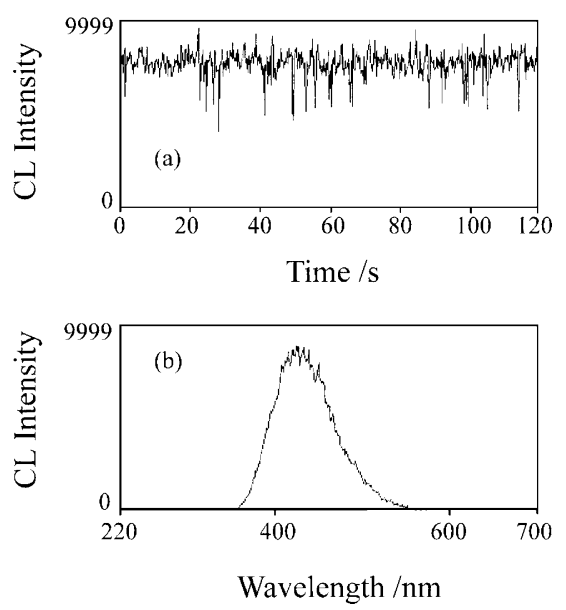

Fig. 8. (a) The time scan of the CL intensity and (b) the CL emission spectrum for the reaction of $2.5 \mu \mathrm{M}$ MP8, $2.5 \mu \mathrm{M}$ $\mathrm{H}_{2} \mathrm{O}_{2}, 50 \mu \mathrm{M}$ luminol, $0.5 \mathrm{M} \mathrm{Na}_{2} \mathrm{CO}_{3}$ in $5 \mathrm{mM}$ phosphate buffer at $\mathrm{pH} 10.0$. The PMT voltage was set at $700 \mathrm{~V}$, the bandpass $10 \mathrm{~nm}$, the emission wavelength (for (a)) $425 \mathrm{~nm}$, and the scan rate (for (b)) $240 \mathrm{~nm} \mathrm{~min}^{-1}$.

lishment of the steady-state signal, the CL emission spectrum can then be determined by a fluorimeter as illustrated in Fig. 8b. The emission spectrum exhibits a maximum at $425 \mathrm{~nm}$, which is the characteristic emission for the excited 3-AP [21]. No other emission bands were observed. Therefore, any contribution to the CL enhancement must be related directly or indirectly to a fast production of a large quantity of the excited 3-AP.

A potential candidate for the additional $\mathrm{CL}$ enhancement is the possible presence of hydroxyl radical $\left(\mathrm{OH}^{\bullet}\right)$ during the formation of the intermediate X (Eq. (1)). Carbonate and bicarbonate are known to react effectively with $\mathrm{OH}^{\bullet}$ to form the carbonate radical $\left(\mathrm{CO}_{3}^{-} \cdot\right)$ with second-order rate constants of $3.65 \times 10^{8}$ and $3.6 \times 10^{7} \mathrm{M}^{-1}$ $\mathrm{s}^{-1}$, respectively, [24].

$$
\begin{aligned}
& \mathrm{CO}_{3}^{2-}+\mathrm{OH}^{\cdot} \rightarrow \mathrm{CO}_{3}^{\cdot-}+\mathrm{OH}^{-} \\
& \mathrm{HCO}_{3}^{-}+\mathrm{OH}^{\cdot} \rightarrow \mathrm{CO}_{3}^{--}+\mathrm{H}_{2} \mathrm{O}
\end{aligned}
$$

The $\mathrm{CO}_{3}^{\bullet-}$ radical reacts very efficiently with luminol to form a luminol radical:

$$
\mathrm{CO}_{3}^{\cdot-}+\mathrm{LH}^{-} \rightarrow \mathrm{CO}_{3}^{2-}+\mathrm{L}^{\cdot-}+\mathrm{H}^{+}
$$

The rate constant for Eq. (7) is $9 \times 10^{8} \mathrm{M}^{-1} \mathrm{~s}^{-1}$ [24]. These reactions will provide an alternate pathway to produce $\mathrm{L}^{\cdot-}$, leading to additional CL enhancement. Tris may undergo a similar pathway to form Tris radical and then $\mathrm{L}^{\cdot-}$, though the efficiency may be smaller than that of carbonate. It is also possible that the presence of enhancer accelerates steps 3 and 4 in the mechanism of $\mathrm{CL}$ emission and also increases the CL quantum yield, leading to a further CL enhancement.

\subsection{Determination of the antioxidants}

The CL system can be applied to detect any one of its reaction components, including CL substrate, oxidant and catalyst. Moreover, any reagents that enhance or inhibit the CL emission can also be determined. Antioxidants react readily with any reactive oxygen species (e.g. $\mathrm{O}_{2}^{-}, \mathrm{H}_{2} \mathrm{O}_{2}$ ) and radicals. The presence of antioxidants is expected to inhibit the CL emission of the MP8luminol- $\mathrm{H}_{2} \mathrm{O}_{2}$ system. As an illustration of the application of this enhanced CL system, the detection of ascorbic acid (a natural antioxidant in the human body) was demonstrated. Fig. 9 shows the CL intensity versus time profiles for the reaction of $2.4 \mu \mathrm{M}$ MP8, $2.4 \mu \mathrm{M} \mathrm{H}_{2} \mathrm{O}_{2}, 50 \mu \mathrm{M}$ luminol, $0.5 \mathrm{M} \mathrm{Na}_{2} \mathrm{CO}_{3}(\mathrm{pH}$ 10.0) at various

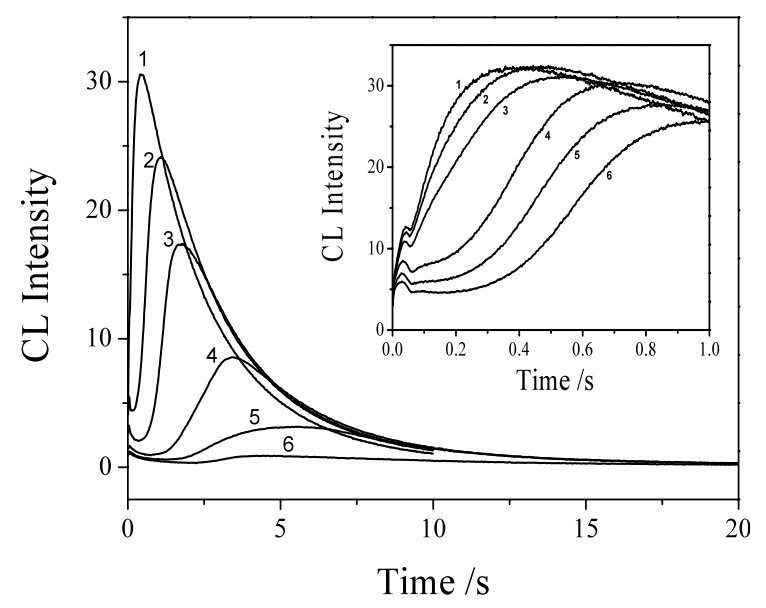

Fig. 9. The stopped-flow CL intensity vs. time profiles for the reactions of $2.4 \mu \mathrm{M} \mathrm{MP} 8,2.4 \mu \mathrm{M} \mathrm{H}_{2} \mathrm{O}_{2}, 50 \mu \mathrm{M}$ luminol, and $0.5 \mathrm{M} \mathrm{Na}_{2} \mathrm{CO}_{3}$ (pH 10.0) in the presence of various concentration of ascorbic acid. The concentrations of ascorbic acid are: 0 , $1.0,2.5,5.0,7.5$, and $10.0 \mu \mathrm{M}$ (from 1 to 6 ); $0,0.05,0.10,0.50$, 0.75 , and $1.0 \mu \mathrm{M}$ (inset, from 1 to 6 ). 
concentrations of ascorbic acid. The addition of $0.01-1 \mu \mathrm{M}$ of ascorbic acid to the CL system decreases the CL intensity only slightly, whereas the occurrence of the CL emission is significantly delayed (Fig. 9, inset). The CL emission depends on the continuous production of free radicals derived from luminol, carbonate, etc. The light emission will be depressed by radical scavenging (chain-breaking) antioxidants but will be restored when all the added antioxidants have been consumed. The presence of ascorbic acid at a concentration of $1-10 \mu \mathrm{M}$ significantly diminishes the CL intensity, accompanied by a concomitant increasing delay of the CL emission (Fig. 9). Relative large amount of antioxidants will destroy most of the free radicals produced, leading to a significantly diminished and delayed CL emission. The time at peak CL intensity $\left(t_{\max }\right)$ and the reduction in CL intensity caused by the addition of ascorbic acid allow the determination of its concentration as illustrated in Fig. 10. The value of $t_{\max }$ increases linearly (Fig. 10a), while the peak CL intensity decreases exponentially (Fig. 10b)
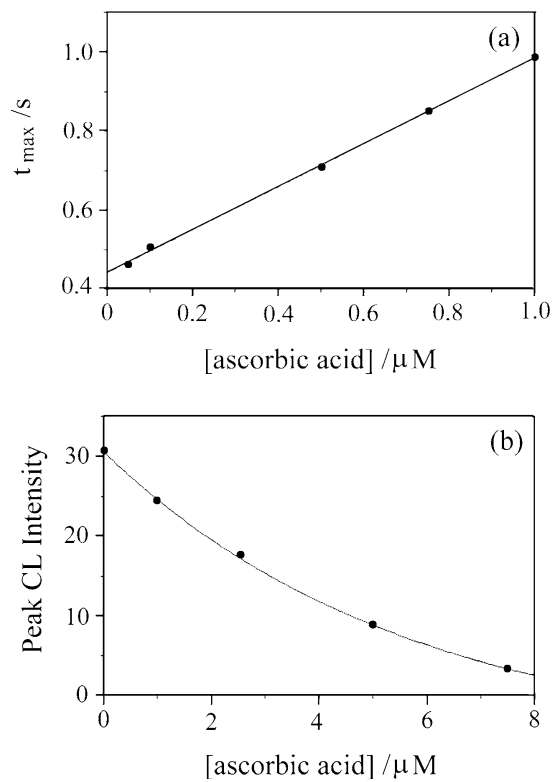

Fig. 10. The plots of (a) $t_{\max }$ and (b) peak CL intensity $\left(I_{\mathrm{CL}}\right)$ vs. the concentration of ascorbic acid (denoted as c) using the data in Fig. 9. The straight line in (a) is given by $t_{\max }=0.438+$ $0.544 \mathrm{c}$, while the smooth curve in (b) is given by $I_{\mathrm{CL}}=-6.69+$ $37.2 \mathrm{e}^{-0.176 \mathrm{c}}$. with the increasing concentration of ascorbic acid. Similar results were also observed for another antioxidant uric acid (data not shown). The results demonstrate the feasibility of employing this CL system as a sensitive means for the determination of the antioxidant, especially when $\mathrm{Na}_{2} \mathrm{CO}_{3}$ or Tris is present.

\section{Conclusion}

The CL intensity of the MP8-luminol- $\mathrm{H}_{2} \mathrm{O}_{2}$ system is enhanced dramatically by the presence of $\mathrm{Na}_{2} \mathrm{CO}_{3}$ or Tris, especially at $\mathrm{pH}$ below 10.0. The CL enhancement caused by the readily available reagents allows the sensitive $\mathrm{CL}$ experiments be carried out over a wide $\mathrm{pH}$ range (10-12.5). The acceleration of the formation of the reactive intermediate of MP8 plays an important role in the CL enhancement. The possible formation of carbonate or Tris radical provides an alternate pathway to produce the luminol radical, leading to a further $\mathrm{CL}$ enhancement. The presence of antioxidant results in a diminished and delayed $\mathrm{CL}$ emission, allowing the determination of its concentration at sub-micromolar level.

\section{Acknowledgements}

The authors thank the National Science Council of ROC for financial support (NSC 89-2113-M002-057).

\section{References}

[1] K. Robards, P.J. Worsfold, Anal. Chim. Acta 266 (1992) 147.

[2] L.J. Kricka, Anal. Chem. 67 (1995) 499R.

[3] U. Isacsson, G. Wettermark, Anal. Chim. Acta 68 (1974) 339.

[4] W. Rudolf Seitz, J. Phys. Chem. 79 (1975) 101.

[5] W.M. Hardy, W. Rudolf Seitz, D.M. Hercules, Talanta 24 (1977) 297.

[6] T.E. Eriksen, J. Lind, G. Merényi, J. Chem. Soc. Faraday Trans. 177 (1981) 2125.

[7] M.M. Rauhut, A.M. Semsel, B.G. Roberts, J. Org. Chem. 31 (1966) 2431.

[8] L.L. Klopt, T.A. Nieman, Anal. Chem. 55 (1983) 1080. 
[9] M. Nakamura, S. Nakamura, Free Radic. Biol. Med. 24 (1998) 537.

[10] A.S. Haqqani, J.K. Sandhu, H.C. Birnboim, Anal. Biochem. 273 (1999) 126.

[11] P.M. Easton, A.C. Simmonds, A. Rakishev, A.M. Egorov, L.P. Candeias, J. Am. Chem. Soc. 118 (1996) 6619.

[12] A. Navas Diaz, F. Garcia Sanchez, J.A. Gonzalez Garcia, J. Photochem. Photobiol. A: Chem. 87 (1995) 99.

[13] J. Lasovsky, M. Rypka, J. Slouka, J. Lumin. 65 (1995) 25.

[14] O. Hirayama, M. Takagi, K. Hukumoto, S. Katoh, Anal. Biochem. 247 (1997) 237.

[15] H. Arakawa, M. Kanemitsu, M. Maeda, Anal. Sci. 15 (1999) 1269.

[16] J.-S. Wang, H.K. Back, H.E. Van Wart, Biochem. Biophys. Res. Commun. 179 (1991) 1320.
[17] J. Aron, D.A. Baldwin, M.M. Marques, J.M. Pratt, P.A. Adams, J. Inorg. Biochem. 27 (1986) 227.

[18] J.S. Wang, A.L. Tsai, J. Heldt, G. Palmer, H.E. van Wart, J. Biol. Chem. 267 (1992) 15310.

[19] H.-C. Yeh, W.-Y. Lin, Anal. Chim. Acta 442 (2001) 71.

[20] J.H. Spee, M.G. Boersma, C. Veeger, B. Samyn, J. van Beeumen, G. Warmerdam, G.W. Canters, W.M.A.M. van Dongen, I.M.C.M. Rietjens, Eur. J. Biochem. 241 (1996) 241.

[21] E.H. White, D.F. Roswell, Chemiluminiscence 3 (1970) 54.

[22] J. Lind, G. Merenyi, T.E. Eriksen, J. Am. Chem. Soc. 105 (1983) 7655.

[23] W.D. Hewson, L.P. Hager, J. Biol. Chem. 254 (1979) 3182.

[24] G. Merenyi, J. Lind, T.E. Eriksen, J. Phys. Chem. 88 (1984) 2320. 